\title{
A study to designate a National Land Sustainable Plan in Japan: focus on land recycling
}

\author{
M. Taniguchi \\ Graduate School of Environmental Science, Okayama University, Japan
}

\begin{abstract}
Although expansion of urban areas has been promoted by rapid population growth in Japan, the lands that have been deserted as a result of decreased population and office space have been increasing lately in various locations throughout the country. Urban layouts with scattered disused lands are not only inefficient, they are also undesirable in terms of sustainability. Furthermore, issues of how to take measures to meet such a decreasing societal capacity as Japan is facing will be shared among more and more countries. To cope with that decreasing trend appropriately, Japan has proposed a guideline, called the "National Land Sustainable Plan", for nationwide space management. The present study elucidates phenomena that reveal themselves now mainly from the viewpoint of land recycling promotion, actual conditions in the "National Land Sustainable Plan", and similar future plans.

Keywords: National Land Sustainable Plan, urban space recycle, ecological footprint.
\end{abstract}

\section{Introduction}

The policy motivation of space use of national lands should vary generally depending on a country's economic development level. During early stages, with low economic activity, a nation should first establish plans to promote economic activity to make the local community affluent. On the other hand, as the society matures as a result of their promoted economic activity, quality of life issues and concern for sustainability should dominate the planning of policy-makers. Japan has experienced exactly such a change of planning ideas over the past five decades. 
This study is intended to: 1) outline the process of establishing the "National Land Sustainable Plan" in Japan; 2) summarize matters that are being considered in the "National Land Sustainable Plan" at the present stage; 3) examine the actual conditions of present space recycling in Japan; and 4) evaluate environmental independence with particular emphasis on space use on a local scale with the ecological footprint index. Finally, based on the findings obtained during the process of 3) and 4), this study will elucidate how the "National Land Sustainable Plan" might be improved.

\section{Process of establishing the "National Land Sustainable Plan"}

After Japan's defeat in World War II, the national government has promoted the development of industry and national lands under the "Comprehensive National Development Plan." That plan's contents have been revised five times since the first plan was formulated in 1962. It has indicated basic directions of policies to resolve problems facing the Japanese nation in each era, especially urban and local problems resulting respectively from overcrowding and depopulation. It has achieved results related to decentralization of the location of the manufacturing industry and the narrowing of income disparities among regions.

The following are inferred to be the results of the "Comprehensive National Development Plan":

1) Decentralization of industry, education, and other activities

2) Growth of central and core cities

3) Reducing the influx of population into metropolitan areas

4) Preventing pollution and reducing congestion in cities

5) Improvement of living environments in local areas

The following, in turn, are pointed out as issues that remain unsolved:

1) Centralization of urban functions and population in the Tokyo Metropolitan Area and the Tokaido region

2) Increase of depopulated areas

3) Hollowing of central urban areas in local cities

4) Overpopulated areas in large cities left unimproved

5) Lack of concern for a good landscape

6) Soil pollution, water pollution, and illegal dumping as social problems

Viewing the long-term change of Japanese population, as shown in Fig. 1, the population has increased continuously since the "Comprehensive National Development Plan", mentioned above, came into force. Nevertheless, the Japanese population apparently peaked in 2006, and has already started to decline.

\section{Issues for examination in the "National Land Sustainable Plan"}

Taking into account the background described above, Japanese national and local administrations have been working cooperatively to promote a new land plan for 
sustainability instead of the development-oriented "National General Development Program." The "National Land Sustainable Plan" is a comprehensive and basic plan to promote utilization, improvement and conservation of national lands (hereafter referred to as the sustainable formation of national lands), concerning the following items:

1) Use and conservation of land, water and other natural resources of national lands

2) Use and conservation of water areas

3) Prevention and reduction of earthquake disasters, water damage, wind damage, and other disasters

4) Coordination and development of the scale and location of cities and agricultural, mountainous and fisheries villages

5) Proper location of industries

6) Use, development and conservation of transportation facilities, information and communication facilities, research institutes concerning technology and other important public facilities

7) Protection of resources related to culture, welfare, and tourism, and the use and development of related facilities

8) Creation of a good environment, the conservation of other environments, and the creation of beautiful scenery

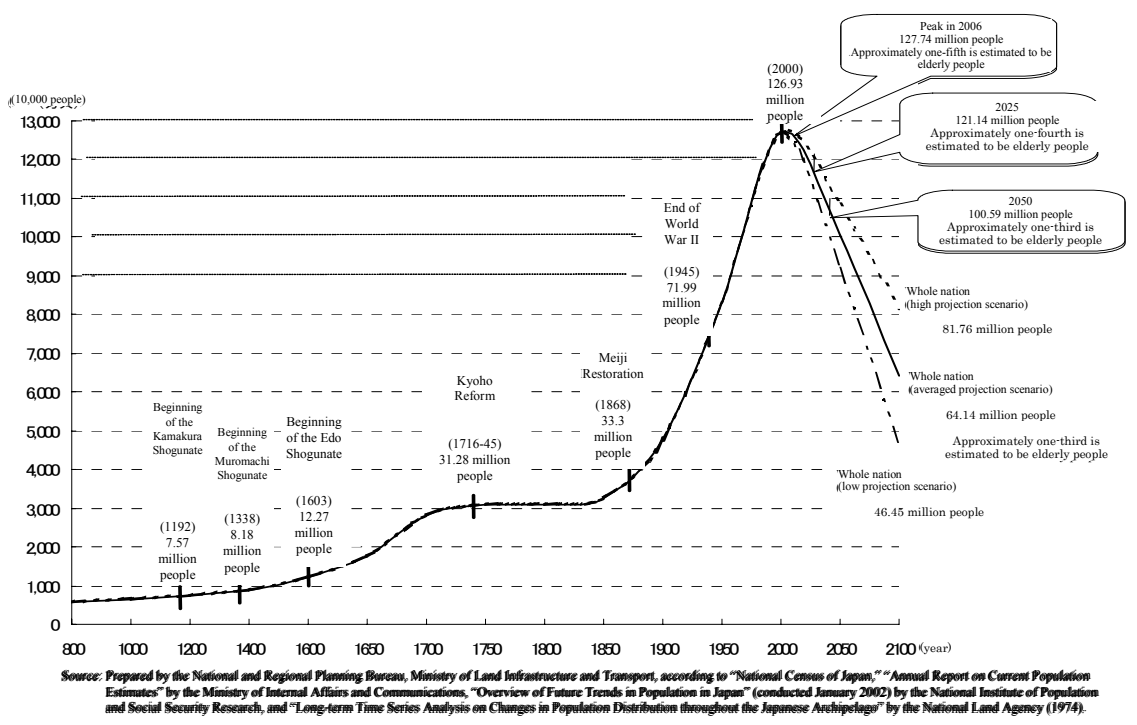

Figure 1: $\quad$ Long-term trend of the total population in Japan.

Above all, the following are shown as examples of problems that are now regarded as important in terms of national land policy and are being investigated.

a) Expansion of areas that have difficulty in providing fundamental social services 
It is presumed that the percentage of small towns with populations of fewer than 5,000 will increase in the future. The data are illustrative: there were 722 towns and villages of less than 5,000 population in 2000 , accounting for $1.7 \%$ of the entire population and $22.9 \%$ of the total area of the nation. In 2050 , those figures are estimated to leap respectively to $3.3 \%$ and $43.2 \%$. In other words, half of all of the national land is expected to be occupied by those small towns and villages. In that situation, it might be difficult to provide even such basic social services as water supply and sewer systems, elementary schools, fire fighting, medical care, etc.

b) Increased cultivation of abandoned lands

Abandoned arable lands increased by 1.4 times during the five years of 1995-2000. The area of such lands is greater than 340,000 ha, equivalent to 1.5 times the area of the Tokyo metropolitan area. Simultaneously, Japan depends on other countries for many agricultural items, which would require 12 million ha of arable land for their production. In addition, regarding forestry, six of ten forestry households own private forests that must be thinned out by owners. Those forests are considered to be virtually abandoned. Moreover, $80 \%$ of the timber consumed in Japan is imported from overseas.

c) Increase in environmental loads

Greenhouse gas emissions in Japan are 1.3 times those of ten years ago. Dumped wastes have actually increased. The loss of biodiversity also presents a serious issue. It is said that 2,663 species inhabiting Japan are in danger of extinction. Therefore, it is necessary to devote greater attention to future development of urban areas.

\section{Actual conditions of space recycling}

\subsection{Preconditions of analysis}

Although a "National Land Sustainable Plan" is being produced on the basis of the various data mentioned above, few sufficient examinations into the issues have been advanced as to how space is reused in an area that has already been urbanized. For that reason, this study shows concretely that the generation of such wasted space is not recycled in the actual case of an urban area. As analyses, both micro and macro methods of examination are used, which respectively address the lot level and grid levels. In addition, no standard of efficiency to assess deserted lands exists because no study has adopted such a viewpoint. Therefore, the micro examination presented in this study originally establishes a standard to evaluate unused land, as shown in Fig. 2, by which a lot that is left as a vacant site or a vacant house is defined as a deserted space.

\subsection{Space recycling at the micro level}

As a concrete sample area, this study presents examination of a suburban arterial road running in Okayama City, a typical district capital. To ascertain the actual conditions of urban space waste and recycling, the author followed up the change 
of land use of the area along the road closely on a micro scale from 1980 to the present. Concretely, the survey was conducted over the entire area of a section $4.5-18 \mathrm{~km}$ from the center of the city along national Route 2 . For measurement, the land along the road was divided into lots as the minimum unit of a land with a building, to illustrate land use (classified into 18 kinds) of each lot using past housing maps and present findings of on-site studies.

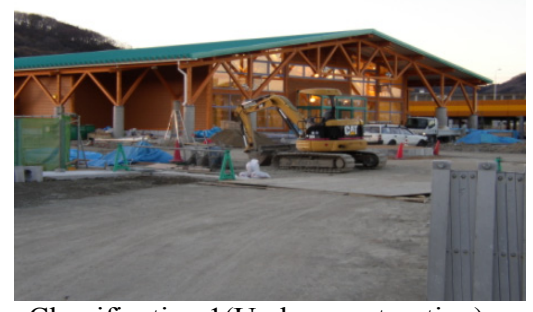

Classification 1(Under construction)

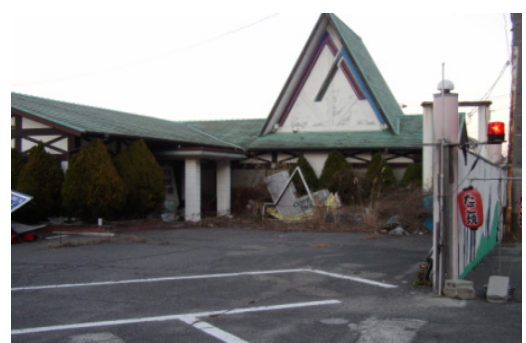

Classification 3(Vacant houses)

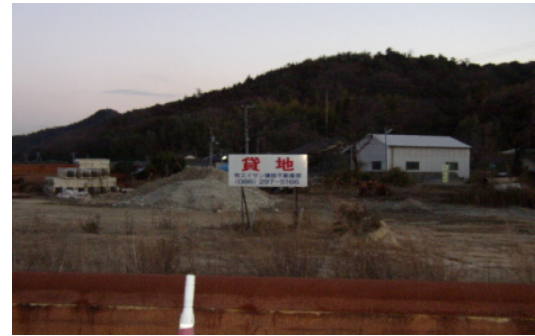

Classification 2(For sale and rent)

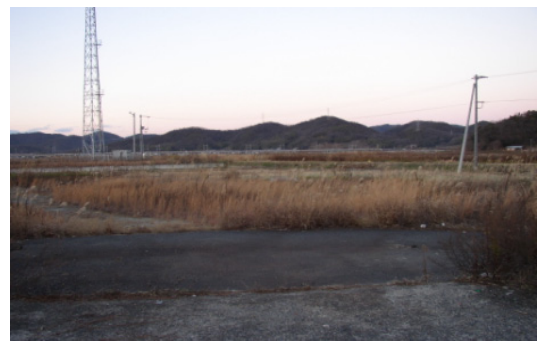

Classification 4(Vacant sites)

Figure 2: Definition of urban space waste and recycle in unused land.
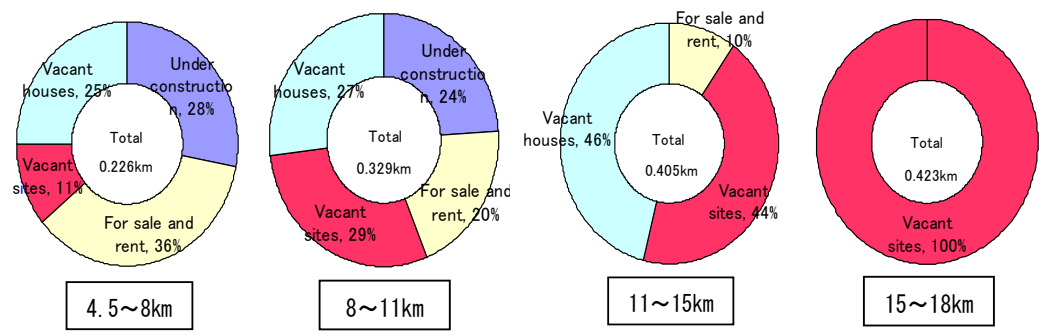

Figure 3: Waste and recycle states of "unused lots".

The tendency throughout the sample area is that the amount of unused land decreased substantially during 1980-1995, meaning that development caused by suburbanization had advanced. Since 1995, in contrast, unused lands have increased. Next, from the viewpoint of space recycling, Fig. 3 depicts the number of present disused spaces such as "vacant lands" or "vacant houses," by 
applying the classifications shown in Fig. 2 exclusively to the lots in which facilities used to exist but which are now disused. Then, the classified total was computed by distance from the city center. Results showed that the absolute quantity of disused land that must be managed from the viewpoint of space recycling is greater in distant suburbs than in nearer suburbs. In other words, the further one travels from the city center, the greater the ratio of space that is not recycled, but is instead left as disused.

\subsection{Space recycling at the macro level}

A macro-level examination was conducted of all commutation areas of Okayama City including results of the analyses presented above ( 5 cities, 14 towns, and 2 villages, with Okayama City and Kurashiki City as the core cities). Main data used here include population according to the national census and the number of employees according to business and enterprise statistics in the local mesh statistics, and land use area of land-use grid data provided by national land numerical information as the land use index. Furthermore, in this study, the sum of the population and the number of employees is designated as the "active total population." The land use classifications of land use mesh data are aggregated into natural land use and urban land use; they can be compared to estimate the actual conditions of space recycling.

To verify at the macro level whether space recycling has been actually promoted in the meshes where the activity has been on the decline, the change of land use was analyzed in districts where the "active total population" had decreased during 1985-1995. Concretely, the grid areas showing substantial decreases (decrease of "active total population" of more than 50) in the surveyed areas are taken as samples. Fig. 4 shows the spatial distribution of the change of natural land use in districts whose "active total population" has been declining. Results shows that the districts with decreased "active total population" are 422 grid areas, of which four grid areas are the districts with increased natural land use, 294 show no change, and 124 are the districts with decreased natural land use. In other words, although the "active total population" has decreased in most districts, the decrease of "active total population" is prominent in the developed districts, where land is simultaneously left as designated for urban use and abandoned.

\section{The possibility of environmental independence in space use (from ecological footprint)}

\subsection{Preconditions of analyses}

Results described in the previous passage indicate that urban land use is not converted into natural land use at all in a non-growing society. If so, then how much of an environmental load attributable to human activity can be absorbed? The ecological footprint (EF) index is one expression of the area that people exploit within (or beyond) biological productive space, such as farms and forests 
providing food and timber, sites for social infrastructure like roads, forests that are converted into absorption of $\mathrm{CO}_{2}$ emission promoting global warming, etc. The EF varies depending on the population scale, the average amount of consumption per capita, and the resource-intensive level of used technology. Although WWF [2] has already promoted examination of the EF index worldwide, there have been few accumulated studies that have examine it specifically at the local level. In this study, referring to the method of WWF, to calculate the environmental loads attributable to human activity, the land areas necessary in the following five items were determined in an original manner.

(1) Arable land to cultivate crops for food and feed $(x=1)$

(2) Pasture to feed livestock for meat and dairy products $(x=2)$

(3) Forest to provide timber and materials for paper manufacture $(x=3)$

(4) Land necessary to provide housing, industry and transportation facilities $(x=4)$

(5) Forest area necessary to fix discharged carbon dioxide $(x=5)$

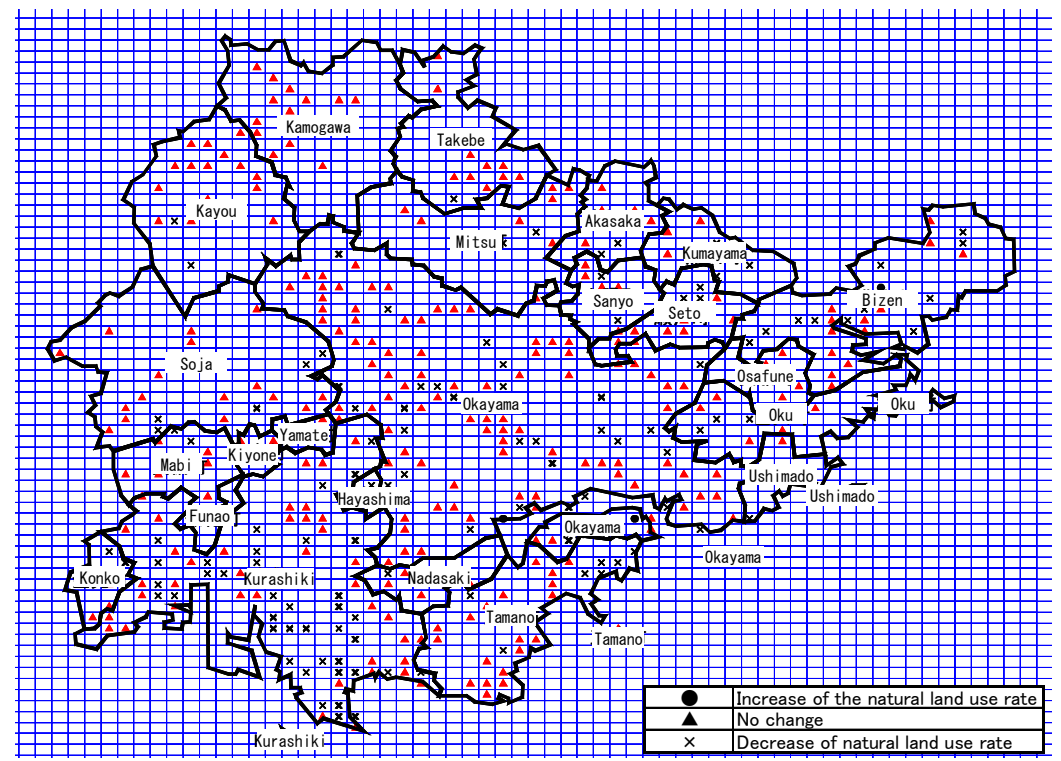

Figure 4: The change of land use at the macro level in grid areas in which "active total population" is on the decline.

\subsection{Formulation}

For this study, land areas that provide food and necessary amenities to live in each city, town, and village, are called "demand areas," whereas the land area producing food and other materials in this country are "supply area." The sum of the demand areas in each item is called the "environmental load"; that of supply areas in each item is called an "amount corresponding to the environment." The difference between both is called the "exceeded footprint." The exceeded 
footprint represents the amount of environmental burden imparted by human systems. The exceeded footprint is defined using eq. (1) in terms of its total amount and net amount.

$$
S^{k}=\sum_{x=1}^{5} S_{d x}{ }^{k}-\sum_{x=1}^{5} S_{s x}{ }^{k}
$$

$S^{k}:$ the total exceeded footprint of municipalities

$S_{d x}{ }^{k}:(x=1-5)$ is the total amount of environmental loads of k municipality $S_{s x}{ }^{k}:(x=1-5)$ is the total amount equivalent to environment of $\mathrm{k}$ municipality

In addition, the amount of imported food and other materials from overseas, as converted into land area, is called the "import area," and the amount of that exported overseas, as converted into land area, is the "export area." The demand area from which the import area is subtracted is called "net environmental load"; the supply area from which the export area is subtracted is called "net amount equivalent to the environment," as defined in eq. (2).

$$
\begin{aligned}
& S_{d}{ }^{k \prime}=\sum_{x=1}^{5}\left(S_{d x}^{k}-A_{I x}^{k}\right) \\
& S_{s}{ }^{k}=\sum_{x=1}^{5}\left(S_{s x}^{k}-A_{E x}^{k}\right)
\end{aligned}
$$

$S_{d}^{k \prime}:$ Net amount of environmental loads of $k$ municipality (without import area) $S_{s}^{k \prime}$ : Net amount equivalent to environment of $k$ municipality (without export area)

$A_{I x}{ }^{k}$ : The import area of $k$ municipality $(x=1-5)$

$A_{E x}{ }^{k}$ : The export area of $k$ municipality $(x=1-5)$

This total exceeded footprint represents the loads not only within the nation but also those extrapolated overseas. This is the land area including the amount that is allocated to producing exports to overseas, as converted into area, which is represented with eq. (1). The other net exceeded footprint represents only the loads within the nation, from which the amount exported to overseas is subtracted, defined as eq. (4).

$$
S^{k \prime}=S_{d}^{k^{\prime}}-S_{s}^{k^{\prime}}
$$

$\mathrm{S}^{\mathrm{k} \prime}$ : Net total exceeded footprint of $k$ municipality

\subsection{Results of examination into the ecological footprint}

Total and net EF excess rates are shown in Fig. 5. It is clarified that the total amount equivalent to the environment exceeds the total amount of the environmental load only in depopulated Kamogawa town, and that the other municipalities effectively import land area from overseas. As shown in Fig. 5, although the net EF excess rates distribute under 5.0 commonly among countries, total EF excess rates are substantially different. Although the total EF excess 
rates in Okayama City, with a large population, and Kurashiki City with developed industrial sites are large, it is the smallest in Kamogawa town. Municipalities with net EF excess rates greater than 1.0, in other words, those that depend on other national municipalities, such as Okayama City, Kurashiki City, and others, account for some $70 \%$ of the areas targeted for the present analysis. The analytical results suggest that it is actually difficult to balance the occurrence of ecological loads with the absorption of ecological loads. To bring ecological accounts more closely into balance, as in Kamogawa town, it is necessary to advance the ideas of space recycling.

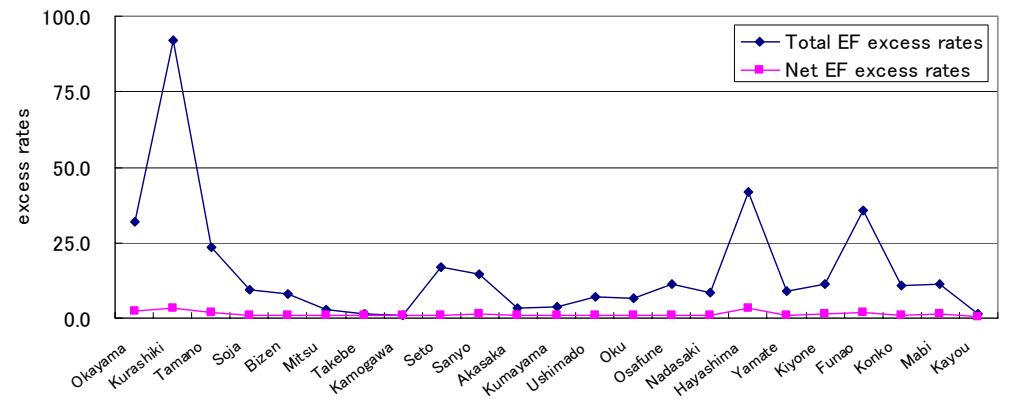

Figure 5: The total Ecological Footprint excess rates and the net Ecological Footprint excess rates by municipalities.

\section{Conclusion}

To realize sustainability in the "National Land Sustainable Plan" that is being made now, it is worth considering that the plan should have some legal force. For that purpose, it is desirable to have a set of convenient indexes by which to judge the degree to which the purpose has been achieved. To reduce external ecological loads to the greatest amount possible, it is extremely important to demand that each local administrative area calculate its EF index. Simultaneously, it might be also important to measure the effects of space recycling and thereby establish a target value of space recycling in each region using the EF index. A system of monitoring the state of achievement of a national land plan is necessary from the viewpoint of sustainability.

\section{References}

[1] National Planning Division, National and Regional Planning Bureau, Ministry of Land, Infrastructure and Transport, Japan: National Land Sustainability Planning System Reform, 2006.

[2] WWF Japan: Living Planet Report 2002 http://www.wwf.or.jp/lib/ publication/downloadfiles/lpr/Final_LPR_2002_pp_01-36.pdf. 
166 Management of Natural Resources, Sustainable Development and Ecological Hazards

[3] Taniguchi, M., Abe, H. and Shigekane, K.: Prefectural Balance Sheet of the Environment: Study Based on the Ecological Footprint, Studies in Regional Science, Vol. 34, No. 1, pp. 23-36, 2004. 